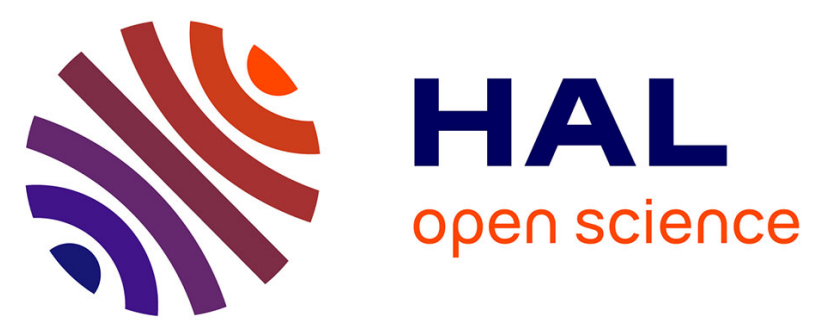

\title{
Risk factors of clinical dysimmune manifestations in a cohort of 86 children with 22q11.2 deletion syndrome: A retrospective study in France
}

Perrine Mahé, Nicolas Nagot, Pierre Portales, Claire Lozano, Thierry Vincent, Pierre Sarda, Marie-Jose Perez, Pascal Amedro, Grégory Marin, Eric Jeziorski

\section{To cite this version:}

Perrine Mahé, Nicolas Nagot, Pierre Portales, Claire Lozano, Thierry Vincent, et al.. Risk factors of clinical dysimmune manifestations in a cohort of 86 children with 22q11.2 deletion syndrome: A retrospective study in France. American Journal of Medical Genetics Part A, 2019, 179 (11), pp.22072213. 10.1002/ajmg.a.61336 . hal-02275678

\section{HAL Id: hal-02275678 \\ https://hal.science/hal-02275678}

Submitted on 11 Jun 2020

HAL is a multi-disciplinary open access archive for the deposit and dissemination of scientific research documents, whether they are published or not. The documents may come from teaching and research institutions in France or abroad, or from public or private research centers.
L'archive ouverte pluridisciplinaire HAL, est destinée au dépôt et à la diffusion de documents scientifiques de niveau recherche, publiés ou non, émanant des établissements d'enseignement et de recherche français ou étrangers, des laboratoires publics ou privés. 


\title{
Risk factors of clinical dysimmune manifestations in a cohort of 86 children with 22q11.2 deletion syndrome: A retrospective study in France
}

\author{
Perrine Mahé $^{1}$ | Nicolas Nagot ${ }^{2}$ | Pierre Portales ${ }^{3}$ | Claire Lozano ${ }^{3}$ | \\ Thierry Vincent $^{3}$ | Pierre Sarda ${ }^{4}$ | Marie-Jose Perez ${ }^{4}$ | Pascal Amedro ${ }^{5}$ | \\ Gregory Marin $^{2}$ | Eric Jeziorski, ${ }^{1,2}$
}

\begin{abstract}
${ }^{1}$ Division of Infectious Diseases, Department of Pediatrics, CHU Montpellier,Univ

Montpellier, Montpellier, France

${ }^{2}$ Pathogenesis and Control of Chronic Infections, Univ. Montpellier, INSERM, EFS and $\mathrm{CHU}$ Montpellier, Montpellier, France

${ }^{3}$ Department of Immunology, $\mathrm{CHU}$ Montpellier, Univ Montpellier, Montpellier, France

${ }^{4}$ Department of Genetics, CHU Montpellier, Univ Montpellier, Montpellier, France

${ }^{5}$ PhyMedExp, CNRS, INSERM, University of Montpellier, Department of Pediatrics, M3C Regional Reference CHD Centre, $\mathrm{CHU}$ Montpellier, Montpellier, France
\end{abstract}

\section{Correspondence}

Perrine Mahé, Division of Infectious Diseases, Department of Pediatrics, CHU Montpellier, University of Montpellier, 371, avenue Doyen Gaston Giraud, Montpellier 34090, France. Email: p-mahe@chu-montpellier.fr

\begin{abstract}
In this study, we describe the biological immune profiles and clinical dysimmune manifestations (infections, autoimmune diseases, and allergies) of patients with 22q11.2 deletion syndrome with the aim of determining risk factors for clinical events. This retrospective study concerned all the patients with 22q11 deletion syndrome attending the Montpellier University Hospital from January 1, 1992, to December 31, 2014 who had at least one immune investigation before the age of 18. We analyzed the clinical features, biological tests and the course of infections, autoimmunity, and allergy of 86 children. Among these 86 children, 48 (59\%) had a low T lymphocyte level. Twenty-nine patients (34\%) had a severe infection. The only risk factor for severe infection was the low level of CD4+ T-cells (OR: 3.3; 95\% confidence interval (Cl) [1.020-11.108]). Eleven patients (13\%) developed an autoimmune disease; the only risk factor was an antecedent of severe infection (OR: $4.1 ; 95 \% \mathrm{Cl}$ [1.099-15.573]). Twenty-three patients (27\%) had allergic episodes. A low level of CD8+ T-cells (OR: 3.2; 95\% Cl [1.07-9.409]) was significantly associated with allergy manifestations. Patients with 22q11 deletion syndrome have a high rate of dysimmune manifestations. We found statistic correlations among CD4+ T-cell count, infectious manifestations, and autoimmunity.
\end{abstract}

KEYWORDS

22q11 deletion syndrome, autoimmunity, dysimmunity, infections, lymphocytes

\section{1 | INTRODUCTION}

The $22 q 11.2$ deletion syndrome (22q11.2 DS) is the most common congenital chromosome deletion syndrome. It is caused by a microdeletion of the long arm of chromosome 22, occurring in one child out of 4,000 live births (Hacıhamdioğlu, Hacıhamdioğlu, \& Delil, 2015). The original description emphasized the thymic hypoplasia or aplasia, parathyroid hypoplasia, cardiac anomalies, and a cleft palate. Other phenotypic features include congenital heart defects, velopharyngeal insufficiency with or without cleft palate, characteristic facial features, developmental delay, learning difficulties, psychiatric conditions, recurrent infections, autoimmunity, and hypocalcemia (Sullivan, 2004). Immune disorders are mainly caused by haploinsufficiency of the transcription factor TBX1, leading to the impaired development of the thymus (Kobrynski \& Sullivan, 2007). A small minority of patients with 22q11.2 DS presents an absent thymus with severe T-cell deficit 
compared to the severe combined immunodeficiency (SCID). More commonly, the thymus is hypoplastic, resulting in a mild to moderate decrease in T-cell numbers (Sullivan, 2004). These patients therefore present dysimmune manifestations such as immunodeficiency and/or autoimmunity and/or allergy.

In the literature, few studies have analyzed the link between the immunological impairments related to this syndrome and their clinical manifestations; the increased susceptibility to infections and autoimmune diseases (Gennery, 2012; Morsheimer, Brown Whitehorn, Heimall, \& Sullivan, 2017; Suksawat et al., 2017; Sullivan, 2004) has been reported, but without defining a profile or characteristics of patients with a particular risk of clinical complications.

The objectives of this study were to describe the immunobiological profiles of patients presenting with 22q11.2 DS, to estimate the prevalence and severity of dysimmune manifestations, and to determine the biological and clinical factors associated with these dysimmune manifestations.

\section{2 | METHODS}

We implemented a single center cohort study for all patients with 22q11.2 DS followed at the Montpellier University Hospital, which is the regional reference center for this syndrome.

\section{1 | Population}

Patients with 22q11.2 DS attending the Montpellier University Hospital from January 1, 1992, to December 31, 2014, were selected for this retrospective study. For the majority of patients, $22 q 11.2$ deletion was confirmed using blood chromosome with in situ hybridization of probes specific for 22q11.2 region, and using array-CGH for the remaining patients. We included patients who had at least one immune investigation before the age of 18 . Among the 137 patients of this cohort, 13 patients did not have an immune investigation and were excluded.

All patients were followed in a specific cohort with programmed visits. If necessary, they were hospitalized according to the medical conditions. We retrospectively collected the following from medical records: palatal anomalies (complete or incomplete cleft palate [bifid uvula, submucosal cleft, soft palate cleft, soft and hard palate cleft, velopharyngeal insufficiency]); cardiac anomalies (conotruncal or not conotruncal; operated or not); severe infections (all infections requiring hospitalization to administer specific treatment, not possible in-home care [oxygen therapy in cases of bronchiolitis, intravenous antibiotic treatment, resuscitation]); autoimmune diseases (juvenile idiopathic arthritis (JIA), immune thrombocytopenic purpura, autoimmune neutropenia, autoimmune hypo- or hyperthyroidism, celiac disease, diabetes, ulcerative colitis); allergies (as detected by a systematic interrogation) (eczema, rhinitis, conjunctivitis, milk allergy, asthma, urticaria, angioedema, and anaphylactic shock).

The plasma level of immunoglobulin G, A, and $M(\operatorname{lgG}, \lg A, \lg M)$ was collected. We used different breakpoints of analysis, depending on the type of the disease. For autoimmune diseases and allergies, we kept the first level of auto-antibodies performed after the age of 2 years to avoid the level of maternal auto-antibodies; for infectious diseases, we preferred to keep the levels achieved after 6 months, because half of the severe infections occurred before the age of 2 years (between 6 and 18 months).

The absolute count of the lymphoid cell subsets was determined by using the total lymphocyte count from the full blood count. The lymphocyte subpopulation phenotyping was performed by flow cytometry on peripheral whole blood collected in an EDTA tube. Subsets were quantified as a relative count, using a panel of fluorescent monoclonal antibodies (Beckman Coulter, CA), targeting the CD3, CD4, and CD8 T-cell markers, the CD19 B-cell marker, and the CD56 NK cell marker.

\section{2 | Statistical analyses}

To find the risk factors of infections, autoimmune diseases, and allergies, we analyzed the clinical and laboratory data. We first realized the univariate analysis. Variables with a $p$-value less than .20 in univariate analysis were used for the multivariate model. This was performed with the stepwise regression. Only the variables whose $p$-value was less than .05 after the procedure were considered significant.

Biological values of lymphocyte phenotyping and immunoglobulins levels were compared to age-matched baseline values: for lymphocyte phenotyping, we compared our data with reference values currently used in France (Picard, 2007); for the immunoglobulins, these were the standards used by the immunology laboratory of the University Hospital of Montpellier, from the data of the International Federation of Clinical Chemistry (IFCC).

\section{3 | RESULTS}

Among the 119 patients with a diagnosis of 22q11.2 DS, all had immune investigation. For 33 patients, these analysis were done after the age of 18 , and could not be considered for analysis, then 86 had an immune investigation before the age of 18 and have been therefore included. There were 45 males (52\%) and 41 females (48\%), with a median age at the diagnosis of 10 months (0.82 years) (10th-90th percentile: $0-10.49$ years). The median duration of follow-up was 6.55 years (10th-90th percentile: 0.86-15.95 years).

\subsection{Immune tests}

Eighty-two patients (95\%) had a lymphocyte phenotyping, and 81 patients (94\%) had a level of immunoglobulins, including 69 (80\%) after the age of 6 months. The initial lymphocyte phenotyping was done at a median age of 4 years (10th-90th percentile: $0.22-13.35$ years). Similarly, the first immunoglobulin level was done at 4 years (10th-90th percentile: 0.36-10.43 years).

Forty-eight of 82 patients (59\%) had a T lymphopenia with a median level of $1.442 .10^{9} / \mathrm{L}$ CD3 + T-cells (10th-90th percentile: 
0.856-2.623.10\%/L CD3 + T-cells), with 52\% [43/82] of low T-CD4 cells (median: $0.800 .10^{\circ} / \mathrm{L} \mathrm{T-CD4}$ cells; 10-90th percentile: $0.404-1.568 .10^{9} / \mathrm{L}$ T-CD4cells). Only 8 patients (9\%) had a very low T-CD4 cells level $\left(<0.400 .10^{9} / \mathrm{L}\right) .48 \%$ [39/82] of low T-CD8 cells (median: $\quad 0.434 .10^{9} / \mathrm{L} \mathrm{T-CD8cells/;} \mathrm{10th-90th} \mathrm{percentile:}$ $\left.0.226-1.108 .10^{9} / \mathrm{L} \mathrm{T}-\mathrm{CD} 8\right)$. Values were compared with the national reference values, which are age-relative ${ }^{5}$. Only $10 \%$ of patients had a B lymphopenia, with a median level of $0.593 .10^{\circ} / \mathrm{L}$ B-cells (10th-90th percentile: $0.260-1.574 .10^{9} / \mathrm{I} \mathrm{B}$-cells). Lymphopenia was more pronounced before 1 year of age, as shown in the Figure 1.

None of the patients had abnormal IgG (median: $9.63 \mathrm{~g} / \mathrm{L} ; 10$ th90th percentile: $6.29-13.72 \mathrm{~g} / \mathrm{L}$ ), but 6 (9\%) had low IgA (median: $0.98 \mathrm{~g} / \mathrm{L} ; 10$ th-90th percentile: $0.27-1.99 \mathrm{~g} / \mathrm{L})$ and 20 (29\%) had low IgM (median: $0.55 \mathrm{~g} / \mathrm{L} ; 10$ th-90th percentile: $0.35-1.04 \mathrm{~g} / \mathrm{L}$ ). Only 4/69 patients (6\%) had hypogammaglobulinemia $A$ and $M$.

\subsection{Clinical impact}

\subsection{1 | Severe infections}

Twenty-nine patients (34\%) experienced a severe infection (Table 1), including 11 (13\% of the cohort) with more than one episode. These episodes occurred at a median age of 1.5 years (10th-90th percentile: 0.08-12.2 years). Of these 29 patients, 13 were hospitalized before the age of 1 year. No patient died of severe infection.
In addition to severe infections, three patients had nonsevere bronchiolitis, one had gastroenteritis, and one had an episode of febrile convulsion. Therefore, 34 patients (40\%) had at least one hospitalized infectious episode. In this group, 20 presented cardiac malformation (odds-ratio: 1.968) and 23 a palatal anomaly (odds-ratio: 0.685). In both instances, the association was not significant (Table 2). T-CD4 lymphopenia was significantly associated with the severe infections in multivariate analysis $(p=.0439)$. Patients with low TCD4 concentration had 3.3 times more risk of severe infection $195 \%$ Cl [1.020-11.108]; Table 2). In our cohort, 9/82 patients (11\%) received long-term antibiotherapy or antibiotic prophylaxis (1 pentamidine aerosolization, 1 azithromycin, 6 co-trimoxazole, and 1 metronidazole for chronic ulcerative colitis). Among these patients, five had a CD4 lymphopenia. Among the 43 patients with low CD4-T cell count, 38 did not have any antibiotic prophylaxis, and no one developed an opportunistic infection.

\subsubsection{Autoimmune diseases}

In our cohort, 11 patients (13\%) developed an autoimmune disease (Table 3). The most frequent diseases were autoimmune thyroiditis $(N=4,5 \%)$, idiopathic juvenile arthritis $(N=2,2 \%)$, and immune thrombocytopenic purpura (ITP) ( $N=2,2 \%)$. The median age of diagnosis was 8 years (10th-90th percentile: $1-12$ years), ranging from 1 to 21 years.

FIGURE 1 Median of lymphocytes compared to normal. (a) T Lymphocytes, (b) T-CD4 Lymphocytes, (c) T-CD8 Lymphocytes. $\triangle$ : median of lymphocytes of patients at 1 year, 2 years, 6 years, 12 years, and 18 years. median of lymphocytes of our cohort. French normal values of the median of lymphocytes [Color figure can be viewed at wileyonlinelibrary.com]

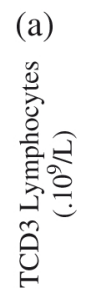

(b)

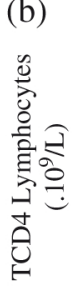

(a)

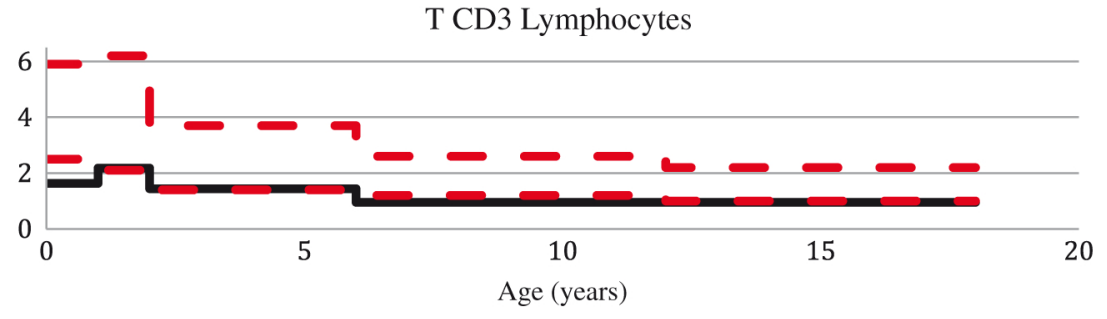

Age (years)

T CD4 Lymphocytes

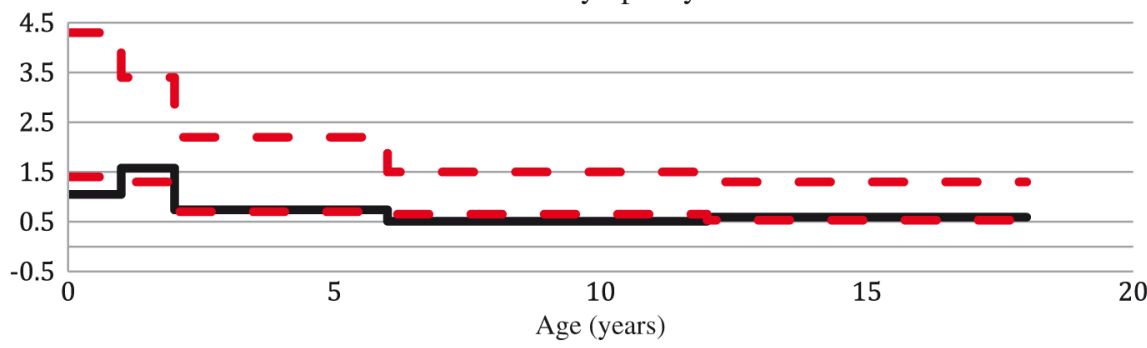

(c)

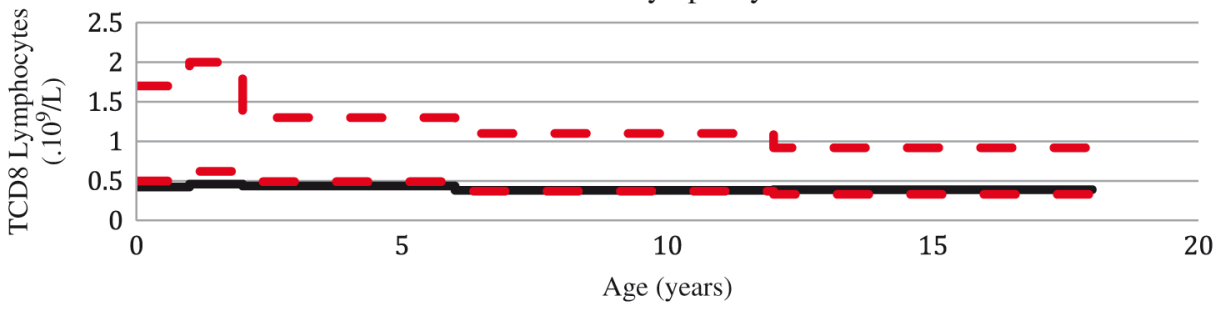


TABLE 1 Severe infections in our population

\begin{tabular}{|c|c|c|c|}
\hline Severe infections & Number of patients $N$ & $\begin{array}{l}\text { Percentage of } \\
\text { total patients (\%) }\end{array}$ & Median age (years) \\
\hline \multicolumn{4}{|l|}{ Respiratory } \\
\hline Bronchiolitis & 8 & $9 \%$ & 1 \\
\hline Pneumonia & 9 & $10 \%$ & 1 \\
\hline Pneumonia with septic shock & 1 & $1 \%$ & 0.31 \\
\hline Influenzae virus & 2 & $2 \%$ & 7.6 \\
\hline \multicolumn{4}{|l|}{ Digestive } \\
\hline Gastroenteritis & 1 & $1 \%$ & 2.5 \\
\hline Appendiceal peritonitis & 1 & $1 \%$ & 5 \\
\hline \multicolumn{4}{|l|}{ Proven sepsis } \\
\hline Coagulase negative staphylococci sepsis (nosocomial) & 2 & $2 \%$ & 0.4 \\
\hline Sepsis on central line (nosocomial, without bacterial isolation) & 1 & $1 \%$ & 9.5 \\
\hline Maternofetal infection (without bacterial isolation) & 2 & $2 \%$ & 0 \\
\hline Neonatal infection (streptococci A) & 1 & $1 \%$ & 0 \\
\hline Meningococcemia B & 1 & & 3 \\
\hline \multicolumn{4}{|l|}{ Otolaryngology } \\
\hline Febrile status epilepticus (otitis) & 1 & $1 \%$ & 9 \\
\hline Bilateral otitis with paracentesis & 1 & $1 \%$ & 0.6 \\
\hline Herpetic stomatitis & & $1 \%$ & 2.7 \\
\hline Strep throat & 1 & $1 \%$ & 10 \\
\hline \multicolumn{4}{|l|}{ Others } \\
\hline Septic scar with cellulitis & 1 & $1 \%$ & 1 \\
\hline Severe reconversion Epstein Barr virus & 1 & $1 \%$ & 6 \\
\hline Pericarditis post pneumonia & 1 & $1 \%$ & 0.5 \\
\hline Pyelonephritis (Coli) & 1 & $1 \%$ & 2.4 \\
\hline Severe sepsis, without germ & 1 & $1 \%$ & 5.6 \\
\hline Measles (with pneumonia) & 1 & $1 \%$ & 16 \\
\hline Post infection leukoencephalitis & 1 & $1 \%$ & 4.7 \\
\hline
\end{tabular}

In univariate analyses, female gender was associated with the autoimmune diseases $(p<.1)$ but was not significant $(p>.05)$. To contract at least one severe infection was significantly associated with the autoimmune diseases in multivariate analysis $(p=.0358)$. Patients who had a severe infection were four times more likely to develop autoimmune disease $(95 \% \mathrm{Cl}$ [1.099-15.573]; Table 4).

\subsection{3 | Allergies}

Overall, 23 patients (27\%) experienced allergic episodes: two had eczema, three patients showed rhinitis or conjunctivitis and 18 had at least one episode of more severe manifestation (asthma, allergy to cow's milk protein, urticaria, angioedema).

Lymphopenia and low T-CD4 were not significantly associated with allergies in univariate analyses. However, we found a significant independent association between having low CD8 and the occurrence of allergies $(p=.0373)$.
Patients with T-CD8 under the standard norms had three times more risk to develop allergies (95\% Cl [1.07-9.409]).

\section{4 | DISCUSSION}

In this retrospective study, 86/119 patients had an immunological exploration before 18 years old, then $28 \%$ were excluded, that could be a bias. As patient with dysimmune manifestation during childhood would have preferentially immunological explorations, they will be probably overrepresented in analysis cohort of our study. This could be a bias, that have to be considered in the interpretation of results.

For the 86 patients explored, T Iymphopenia and immunoglobulin deficiency were frequent and translated to clinical manifestations such as severe infections (34\%), autoimmune diseases (13\%), and allergic episodes (27\%). Interestingly, a history of severe infection was strongly associated with an increased risk of autoimmune disease. 
TABLE 2 Severe infections: univariate and multivariate analysis of the risk factors of severe infections

\begin{tabular}{|c|c|c|c|c|c|c|c|c|}
\hline \multirow{3}{*}{$\begin{array}{l}\text { Variables } \\
\text { Sex (females vs. males) }\end{array}$} & \multicolumn{4}{|c|}{ Univariate analysis } & \multicolumn{4}{|c|}{ Multivariate analysis } \\
\hline & \multirow{2}{*}{$\begin{array}{l}\text { Odds-ratio } \\
1.277\end{array}$} & \multicolumn{2}{|l|}{$95 \% \mathrm{Cl}$} & \multirow{2}{*}{$\begin{array}{l}p \text {-value } \\
.5920\end{array}$} & \multirow[t]{2}{*}{ Odds-ratio } & \multicolumn{2}{|l|}{$95 \% \mathrm{Cl}$} & \multirow[t]{2}{*}{$p$-value } \\
\hline & & 0.522 & 3.128 & & & & & \\
\hline Prematurity (premature vs. nonpremature) & 2.136 & 0.560 & 8.151 & .2665 & & & & \\
\hline Cardiopathy (presence vs. absence) & 1.968 & 0.745 & 5.198 & .1718 & & & & \\
\hline Operated cardiopathy (operation vs. nonoperation) & 1.358 & 0.547 & 3.367 & .5095 & & & & \\
\hline Palatal anomaly (presence vs. absence) & 0.685 & 0.196 & 2.394 & .5536 & & & & \\
\hline IUGR (IUGR vs. normal weight) & 0.737 & 0.259 & 2.093 & .5664 & & & & \\
\hline Hypoparathyroidism (presence vs. absence) & 1.402 & 0.547 & 3.596 & .4820 & & & & \\
\hline Total lymphocytes (low vs. normal) & 2.375 & 0.925 & 6.100 & .0723 & & & & \\
\hline T lymphocytes (low vs. normal) & 1.965 & 0.732 & 5.274 & .1799 & & & & \\
\hline T-CD4 lymphocytes (low vs. normal) & 3.370 & 1.263 & 8.991 & .0153 & 3.300 & 1.020 & 11.108 & .0439 \\
\hline T-CD8 lymphocytes (low vs. normal) & 1.510 & 0.595 & 3.836 & .3859 & & & & \\
\hline B lymphocytes (low vs. normal) & 1.175 & 0.259 & 5.337 & .8346 & & & & \\
\hline IgG (low vs. normal) & NA & NA & NA & NA & & & & \\
\hline IgA (low vs. normal) & 3.200 & 0.583 & 17.553 & .1804 & & & & \\
\hline IgM (low vs. normal) & 0.897 & 0.271 & 2.967 & .8562 & & & & \\
\hline
\end{tabular}

Note: Bold values represent $p<0.5$ for univariate and multivariate analysis.

Abbreviation: IUGR, intrauterine growth restriction.

TABLE 3 Autoimmune diseases in our population

\begin{tabular}{|llll|}
\hline & $\begin{array}{l}\text { Number of } \\
\text { patients } \mathbf{N}\end{array}$ & $\begin{array}{l}\text { Percentage } \\
\text { of total } \\
\text { patients (\%) }\end{array}$ & $\begin{array}{l}\text { Median } \\
\text { age } \\
\text { (years) }\end{array}$ \\
\hline Auto immune thyroiditis & 4 & $5 \%$ & 10 \\
\hline $\begin{array}{l}\text { Idiopathic juvenile arthritis } \\
\text { Immune thrombocytopenic }\end{array}$ & 2 & $2 \%$ & 4 \\
\hline $\begin{array}{l}\text { purpura } \\
\text { Diabetes }\end{array}$ & 2 & $2 \%$ & 7 \\
\hline Ulcerative colitis & 1 & $1 \%$ & 13 \\
\hline Autoimmune neutropenia & 1 & $1 \%$ & 11 \\
\hline
\end{tabular}

Lymphocyte phenotyping of this cohort correlated with those in the literature (Morsheimer et al., 2017; Suksawat et al., 2017; Sullivan, 2004). Most patients had lymphopenia affecting total lymphocytes (59\%), T-CD4+ (52\%), and T-CD8+ (48\%).

We decided to keep only the first lymphocyte phenotyping performed on the patients at diagnosis in order to approximate clinical practice.

We could not study if patients who had cardiac surgery had deeper T lymphopenia than the other patients because of a lack of data. We did not have the date of the surgeries. We did not know if patients were operated before or after the immune tests.

In our cohort, we did not find any IgG deficiency; however, IgA and/or IgM deficiency were particularly frequent. Some authors showed a normal total number of B-cells but with a low number of memory B-cells $\quad(\mathrm{CD} 27+\lg M+\operatorname{lgD}+$ and $\quad \mathrm{CD} 27+\lg M \quad \operatorname{lgD})$ (Derfalvi, Maurer, McDonald McGinn, et al., 2016; Finocchi, Di
Cesare, Romiti, et al., 2006; Gennery, 2012). It is not clear whether this deficit is related to a direct effect of the 22q11.2 deletion or to a defect in B-T cell interactions. Unfortunately, memory B-cell count, lymphocytes proliferation, and postvaccine serologies were not available for this study. These data were not followed systematically in the hospital.

In this study, patients with CD4 lymphopenia had an increased risk of severe infection. Antibiotic treatment should be used early in case of suspected infection. It is reassuring that no patient suffered from opportunistic infections, despite sometimes very low CD4 cell counts and, most of the time, the absence of antibiotic prophylaxis. This data challenges the recommendation of co-trimoxazole preventive therapy for these patients. Our results seem interesting to reconsider antibiotic prophylaxis but need to be confirmed by larger studies, as only 8 patients ( $9 \%$ ) had a very low CD4 T-cells level $\left(<0.40010^{9}\right.$ cells $\left./ L\right)$. In our cohort, patients were particularly subject to conventional infections, particularly encapsulated bacteria (importance of pneumonia and meningococcemia) before the age of 5 years. It might be of interest to propose a preventive treatment by phenoxymethylpenicillin (penicillin) rather than co-trimoxazole because of the absence of opportunistic infections (toxoplasmosis, pneumocystis). Similarly, these patients were vulnerable to bronchiolitis and may benefit from palivizumab (Synagis), as with other patients with cardiopathy or prematurity. If antibiotic prophylaxis is not enough to prevent regular infections, immunoglobulin infusions should be considered and discussed with the immunologist. These data has been suggested in previous reports (Suksawat et al., 2017; Sullivan, 2004). In this series, the only risk factor for severe infections was a low T-CD4 count, which has never been reported before, probably because other studies 
TABLE 4 Auto immunity: univariate and multivariate analysis of the risk factors of autoimmunity

\begin{tabular}{|c|c|c|c|c|c|c|c|c|}
\hline \multirow{3}{*}{$\begin{array}{l}\text { Variables } \\
\text { Sex (females vs. males) }\end{array}$} & \multicolumn{4}{|c|}{ Univariate analysis } & \multicolumn{4}{|c|}{ Multivariate analysis } \\
\hline & \multirow{2}{*}{$\begin{array}{l}\text { Odds-ratio } \\
3.394\end{array}$} & \multicolumn{2}{|l|}{$95 \% \mathrm{Cl}$} & \multirow{2}{*}{$\begin{array}{l}p \text {-value } \\
.0878\end{array}$} & \multirow{2}{*}{$\begin{array}{l}\text { Odds-ratio } \\
3.595\end{array}$} & \multicolumn{2}{|c|}{$95 \% \mathrm{Cl}$} & \multirow{2}{*}{$\begin{array}{l}\boldsymbol{p} \text {-value } \\
.0886\end{array}$} \\
\hline & & 0.834 & 13.804 & & & 0.824 & 15.678 & \\
\hline Prematurity (premature vs. nonpremature) & 1.906 & 0.343 & 10.601 & .4612 & & & & \\
\hline Cardiopathy (presence vs. absence) & 0.689 & 0.192 & 2.473 & .5682 & & & & \\
\hline Operated cardiopathy (operation vs. nonoperation) & 0.714 & 0.192 & 2.657 & 6157 & & & & \\
\hline Palatal anomaly (presence vs. absence) & 0.738 & 0.139 & 3.924 & .7212 & & & & \\
\hline IUGR (IUGR vs. normal weight) & 0.597 & 0.115 & 3.116 & .5410 & & & & \\
\hline Hypoparathyroidism (presence vs. absence) & 2.836 & 0.783 & 10.276 & .1124 & & & & \\
\hline Total lymphocytes (low vs. normal) & 0.611 & 0.149 & 2.505 & .4939 & & & & \\
\hline T lymphocytes (low vs. normal) & 1.933 & 0.472 & 7.922 & .3596 & & & & \\
\hline T-CD4 lymphocytes (low vs. normal) & 1.103 & 0.308 & 3.946 & .8805 & & & & \\
\hline T-CD8 lymphocytes (low vs. normal) & 2.023 & 0.542 & 7.548 & .2940 & & & & \\
\hline B lymphocytes (low vs. normal) & 0.871 & 0.097 & 7.860 & .9024 & & & & \\
\hline Severe infections (presence vs. absence) & 4.216 & 1.120 & 15.865 & .0333 & 4.136 & 1.099 & 15.573 & .0358 \\
\hline IgM (low vs. normal) & NA & NA & NA & NA & & & & \\
\hline IgA (low vs. normal) & 2.688 & 0.217 & 33.278 & .4413 & & & & \\
\hline IgM (low vs. normal) & 1.192 & 0.258 & 5.505 & .8217 & & & & \\
\hline
\end{tabular}

Note: Bold values represent $p<0.5$ for univariate and multivariate analysis. Abbreviation: IUGR, intrauterine growth restriction.

considered all the infections, not focusing on the severe ones. We did not study the tolerance after receiving the live vaccines in this population because we did not have the data. In other studies, the rate of mild adverse effects was similar to the general population (Hofstetter et al., 2014; Suksawat et al., 2017).

Regarding autoimmune diseases, $13 \%$ of our patients developed these pathologies. In the Jawad study, $10 \%$ of patients had autoimmunity (Jawad, McDonald-McGinn, Zackai, et al., 2001). These figures are much higher than in the general population. For example, the prevalence of JIA in Europe ranges from 0.016 to $0.15 \%$ (HAS, 2009) whereas it was $2 \%$ in our study. Similarly, $2 \%$ of our cohort patients developed an ITP, in contrast with $0.07 \%$ in the general population of American children under 14 years (Segal \& Powe, 2006).

An important limitation of our study was the inability to know the family history of autoimmune disease. In our study, autoimmunity seems to be related to immunodeficiency as described in the publication of A. Fischer (2017). Considering these data, we demonstrated that the clinician needs to follow carefully the risk of autoimmunity for 22q11.2 DS patients with a past history of severe infections. Regarding allergies, $27 \%$ of patients had allergic episodes, with a predominance of asthma. We did not always have detailed biological tests (IgE assay, prick tests), so we classified the patients according to their clinical presentation from the medical records. The prevalence of asthma in our population was $19 \%$ compared to $10 \%$ of the French children aged below 15 in France in 2010 (Rancé, 2010). We found a correlation between allergies and low T-CD8+. Morsheimer et al. (2017) found a link between T-CD3+ and the occurrence of allergies, but not with T-CD4+ or T-CD8+.
Dysimmunity is a main manifestation in the 22q11.2 DS: patients with this syndrome have a higher risk of severe infections, autoimmunity, and allergy than the general population has. We showed that these three parts of dysimmunity are related to each other and to lymphopenia.

To confirm our results, a prospective study to collect naïve and memory population cells, lymphocyte functions, and vaccine responses seems necessary.

\section{ACKNOWLEDGMENTS}

Thank you to Dr Nizar Mahlaoui for his review of the manuscript.

\section{CONFLICT OF INTEREST}

Authors declare not to have conflict of interest with this study.

\section{REFERENCES}

Arthrite Juvénile Idiopathique, PNDS de l'HAS. 2009. Retrieved from http: //www.has-sante.fr/portail/upload/docs/application/pdf/2009-09/ald_31_pnds_arthrite_juvenile_web.pdf

Derfalvi, B., Maurer, K., McDonald McGinn, D., Zackai, E., Meng, W., T. Luning Prak, E., Sullivan, K. E. (2016). B cell development in chromosome 22q11.2 deletion syndrome. Clinical Immunology, 163, 1-9. https://doi.org/10.1016/j.clim.2015.12.004 
Finocchi, A., Di Cesare, S., Romiti, M. L., Capponi, C., Rossi, P., Carsetti, R., Cancrini, C. (2006). Humoral immune responses and CD27+ B cells in children with DiGeorge syndrome (22q11.2 deletion syndrome). Pediatric Allergy and Immunology, 17(5), 382-388. https://doi.org/10. 1111/j.1399-3038.2006.00409.x

Fischer, A., Provot, J., Jais, J. P., Alcais, A., Mahlaoui, N., \& members of the CEREDIH French PID study group. (2017). Autoimmune and inflammatory manifestations occur frequently in patients with primary immunodeficiencies. The Journal of Allergy and Clinical Immunology, 140(5), 1388-1393. https://doi.org/10.1016/j.jaci.2016.12.978

Gennery, A. R. (2012). Immunological aspects of 22q11.2 deletion syndrome. Cellular and Molecular Life Sciences, 69(1), 17-27. https://doi. org/10.1007/s00018-011-0842-z

Hacıhamdioğlu, B., Hacıhamdioğlu, D., \& Delil, K. (2015). 22q11 deletion syndrome: current perspective. The Application of Clinical Genetics, 8, 123-132. https://doi.org/10.2147/TACG.S82105

Hofstetter, A. M., Jakob, K., Klein, N. P., Dekker, C. L., Edwards, K. M., Halsey, N. A., ... LaRussa, P. (2014). Live vaccine use and safety in DiGeorge syndrome. Pediatrics, 133(4), e946-e954. https://doi.org/ 10.1542/peds.2013-0831

Jawad, F. A., McDonald-McGinn, D. M., Zackai, E., Sullivan, K. E. (2001). Immunologic features of chromosome 22q11.2 deletion syndrome (DiGeorge syndrome/velocardiofacial syndrome). The Journal of Pediatrics, 139(5), 715-723. https://doi.org/10.1067/mpd.2001.118534

Kobrynski, L. J., \& Sullivan, K. E. (2007). Velocardiofacial syndrome, DiGeorge syndrome: The chromosome 22q11.2 deletion syndromes. Lancet, 370(9596), 1443-1452. https://doi.org/10.1016/S0140-6736 (07)61601-8

Morsheimer, M., Brown Whitehorn, T. F., Heimall, J., \& Sullivan, K. E. (2017 Sep). The immune deficiency of chromosome 22q11.2 deletion syndrome. American Journal of Medical Genetics. Part A, 173(9), 2366-2372. https://doi.org/10.1002/ajmg.a.38319
Picard, C. (2007). How to diagnose a hereditary immunodeficiency? La Revue du Praticien, 57(15), 1671-1676. https://doi.org/10.1007/ s10875-015-0201-1

Rancé, F., Deschildre, A., Bidat, E., Just, J., Couderc, L., Wanin, S., ... Groupe de recherche sur les avancées en pneumopédiatrie (GRAPP). (2010). Secondary and tertiary prevention of allergic asthma in children. Revue Des Maladies Respiratoires, 27(10), 1221-1230. https:// doi.org/10.1016/j.rmr.2010.06.024

Segal, J. B., \& Powe, N. R. (2006). Prevalence of immune thrombocytopenia: Analyses of administrative data. Journal of Thrombosis and Haemostasis, 4(11), 2377-2383. https://doi.org/10.1111/j.15387836.2006.02147.x

Suksawat, Y., Sathienkijkanchai, A., Veskitkul, J., Jirapongsananuruk, O., Visitsunthorn, N., Vichyanond, P., \& Pacharn, P. (2017). Resolution of primary immune defect in 22q112 deletion syndrome. Journal of Clinical Immunology, 37(4), 375-382. https://doi.org/10.1007/s10875017-0394-6

Sullivan, K. E. (2004). The clinical, immunological, and molecular spectrum of chromosome 22q11.2 deletion syndrome and DiGeorge syndrome. Current Opinion in Allergy and Clinical Immunology, 4(6), 505-512. https://doi.org/10.1097/00130832-200412000-00006 